Bull. Mater. Sci., Vol. 17, No. 6, November 1994, pp. 911-920, (C) Printed in India.

\title{
Electrokinetic behaviour and dispersion characteristics of ceramic powders with cationic and anionic polyelectrolytes
}

\author{
PRADIP, R S PREMACHANDRAN* and S G MALGHAN* \\ Tata Research Development and Design Centre, 1, Mangaldas Road, Pune 411001 , India \\ *Materials Science and Engineering Laboratory, National Institute of Standards and \\ Technology, Gaithersburg, MD 20899, USA
}

\begin{abstract}
Three different ceramic powders, viz. alumina, zirconia and silicon nitride were dispersed using two polyelectrolytes, one cationic (Betz 1190) and the other anionic (Darvan-C). All powders examined during the study could be well dispersed only under conditions of polymer dosage and $\mathrm{pH}$ such that the working $\mathrm{pH}$ is at least $2 \mathrm{pH}$ units away from the $\mathrm{pH}_{\mathrm{IEP}}$ of the powder-dispersant combination. The shift in the isoelectric point (IEP) of the powders were determined through electro-acoustic measurements on $1 \%$ volume suspensions. Specific free energy of interaction were also computed using a model based on the electrical double layer theory of surfactant absorption.
\end{abstract}

Keywords. Electrokinetics; dispersion; alumina; zirconia; silicon nitride; polyelectrolytes; electroacoustophoresis; Darvan-C; Betz 1190.

\section{Introduction}

Colloidal processing techniques are considered to be most promising in the preparation of advanced ceramic products with improved mechanical and electrical properties, partially as a consequence of achieving better homogeneity in the green bodies formed through colloidal routes (Lange 1989). Adequate control of the rheology of concentrated particulate slurries is crucial for the success of such processing methods. For example, the optimum performance of processes like spray drying, injection moulding, slip and tape casting and pressure filtration is dependent on the preparation of a slurry having maximum volume fraction of solids yet exhibiting minimum viscosity (Leong et al 1991). The rheological control is accomplished in practice with the addition of certain reagents (inorganic, organic and polymeric surfactants) known as dispersants (Chou and Lee 1989; Bleier and Westmoreland 1991; Bleier 1992; Bleier et al 1992). The dispersants adsorb at the solid/liquid interfaces and appropriately alter the surface properties of the colloids facilitating desired dispersion. Currently, these surfactants are selected by trial and error, their dosages arrived at based on experience and rules of thumb (Calvert et al 1986). There thus exists a need to develop the science of dispersants design i.e. a methodology to systematically design and/or select dispersants for the specific problem at hand based on our scientific understanding of the surface forces between particles.

Certain trade names and company products are mentioned in the text or identified in illustrations in order to adequately specify the experimental procedure and equipment used. In no case does such identification imply recommendation or endorsement by the authors and their respective institutes nor does it imply that the products are necessarily the best available for the purpose. 
The stability of a dispersed colloid system can be quantitatively described by the classical DLVO (Derjaguin, Landau, Verwey and Overbeek) theory which considers two types of long range forces between colloidal particles; viz. the van der waals London attractive forces and the electrical double layer (attractive or repulsive depending upon the surface charge) forces (Hunter 1981; Israelachvili 1992). The adsorption of charged surfactant species (inorganic, organic or polymeric) at the interfaces leading to repulsive interaction can thus be utilized to achieve stability, i.e. electrosíatic stabilization of colloids (Hogg et al 1966). Another mode of achieving colloidal dispersion, i.e. through the adsorption of relatively long chain polymers, is called steric stabilization. The protective layer of the polymer on the surface gives rise to steric repulsion leading to enhanced colloidal stability (Napper 1983).

It is important to note that electrostatically stabilized dispersions are kinetically stable, but are very sensitive to the presence of electrolytes. With increasing ionic strength, the electrical double layer repulsion is reduced causing coagulation. On the other hand, sterically stabilized dispersions are thermodynamically stable and are relatively more tolerant of the electrolytes. In dispersions stabilized by polyelectrolytes (e.g. polyacrylic acid), both the mechanisms, viz. the electrostatic as well as the steric, are important. Such dispersants are also called electrosteric stabilizers (Sung and Piirma 1994).

The purpose of the ongoing research in our laboratories is to evaluate the effectiveness of various commercial dispersants in ceramics processing as well as to understand the underlying mechanisms of dispersion, particularly in concentrated slurries. It is envisaged that these efforts would enable us to develop a scientific methodology for the design of tailor made dispersants for the specific problems faced by the industry. We present in this paper, the results of our work on the dispersion of ceramic suspensions using two kinds of polyelectrolytes (anionic and cationic). A model based on electrical double layer theory is also presented so as to quantitatively compare the specific interaction between the adsorbing polymer and the colloidal surface.

\section{Experimental}

\subsection{Materials}

Three powder samples, viz. alumina, stabilized zirconia and silicon nitride were selected for this study. The physical and surface chemical characteristics of the powders are summarized in table 1.

Two polyelectrolyte dispersants, viz. Darvan-C (ammonium polymethacrylate), an anionic polymer obtained from Vanderbilt Co., USA and Betz 1190 (quaternized polyamine epoxy chlorohydrin) a cationic polymer supplied by Betz Co., USA, were used in this study. Both the polymers had an average molecular weight around 10,000. All polymer dosages are represented in parts per million (ppm), i.e. mg of polymer per unit volume of solution.

\subsection{Methods}

Matec ESA 8000 system (Matec Applied Sciences, USA) was used for electroacoustic 
Table 1. Physical and surface chemical characteristics of powder samples.

\begin{tabular}{llccc}
\hline Powder & Source & $\begin{array}{c}\text { BET surface } \\
\text { area* } \\
\left(\mathrm{m}^{2} / \mathrm{g}\right)\end{array}$ & $\begin{array}{c}\text { Average } \\
\text { particle size } \\
d_{50}^{* *}(\text { microns })\end{array}$ & $\begin{array}{c}\text { PZC }^{\dagger} \\
(\mathrm{pH})\end{array}$ \\
\hline $\begin{array}{c}\text { Alumina } \\
(\text { A-16) }\end{array}$ & Alcoa, USA & 9.3 & 0.38 & 9.9 \\
$\begin{array}{c}\text { Zirconia } \\
(\text { SY5.2) }\end{array}$ & Z Tech, Australia & 14.9 & 0.21 & 6.65 \\
$\begin{array}{c}\text { Silicon nitride } \\
(\text { SNE-10) }\end{array}$ & Ube, Japan & 10.1 & 0.4 & 6.5 \\
\hline
\end{tabular}

*Micromeritics surface area-pore volume analyzer; **Laser light scattering instrument, HORIBA, LA-9000; ' Matec ESA 8000.

measurements on the powder suspensions $(0.5 \%$ or $1 \%$ by volume). Electrokinetic sonic amplitude (ESA) as a measure of the surface charge on the particle was determined following a standard procedure, as described in detail earlier (Hackley et al 1993). The mobilities are presented in the form of ESA (MPa.m/v), measured during experiments. All the measurements were carried out in $10^{-3} \mathrm{M}$ sodium nitrate solutions at room temperature. The suspensions were prepared in deionized water by ultrasonic dispersion. $\mathrm{pH}$ adjustments were made with the help of analytical grade nitric acid and sodium hydroxide solutions.

The extent of dispersion under given conditions was determined by measuring the particle size distribution of the powder. Under the conditions of perfect dispersion with no coagulated aggregates present in the suspension, the average particle size for the sample $\left(d_{50}\right)$ coincided with the average particle size of the powder. An increase in $d_{50}$ of the powder indicated the presence of aggregates (usually a bimodal particle size distribution was also observed under these conditions) and hence unsatisfactory dispersion. All measurements were carried out at a concentration of $5 \%$ solids by weight $(1 \mathrm{~g}$ solid powder in $20 \mathrm{ml}$ solution); the suspension prepared by ultrasonic dispersion and the size distributions measured by HORIBA LA-900, a laser scattering particle size analyzer (Premachandran and Malghan 1994).

\section{Results and discussion}

The isoelectric point (IEP) for alumina was found to be at $\mathrm{pH} 9.9$ in the absence of dispersant. With increasing addition of anionic dispersant Darvan- $C$, the IEP of the powder measured through ESA measurements was found to shift to more acidic $\mathrm{pH}$ values as shown in figure 1 .

The IEP of zirconia powder was measured to be at $\mathrm{pH} 6.65$. In the presence of a cationic dispersant, Betz 1190 , the IEP of zirconia powder was observed to shift to more alkaline $\mathrm{pH}$ as illustrated in figure 2.

The IEP of silicon nitride powder was observed to occur at $\mathrm{pH} \mathrm{6.5.} \mathrm{The} \mathrm{electrokinetic}$ behaviour of the powder in the presence of anionic (Darvan-C) and cationic (Betz 1190) depresants shown in figure 3 exhibits trends very similar to alumina and zirconia powders. The shift in IEP was towards acidic $\mathrm{pH}$ with an addition of anionic polymer and towards alkaline $\mathrm{pH}$ in the presence of a cationic polymer. 


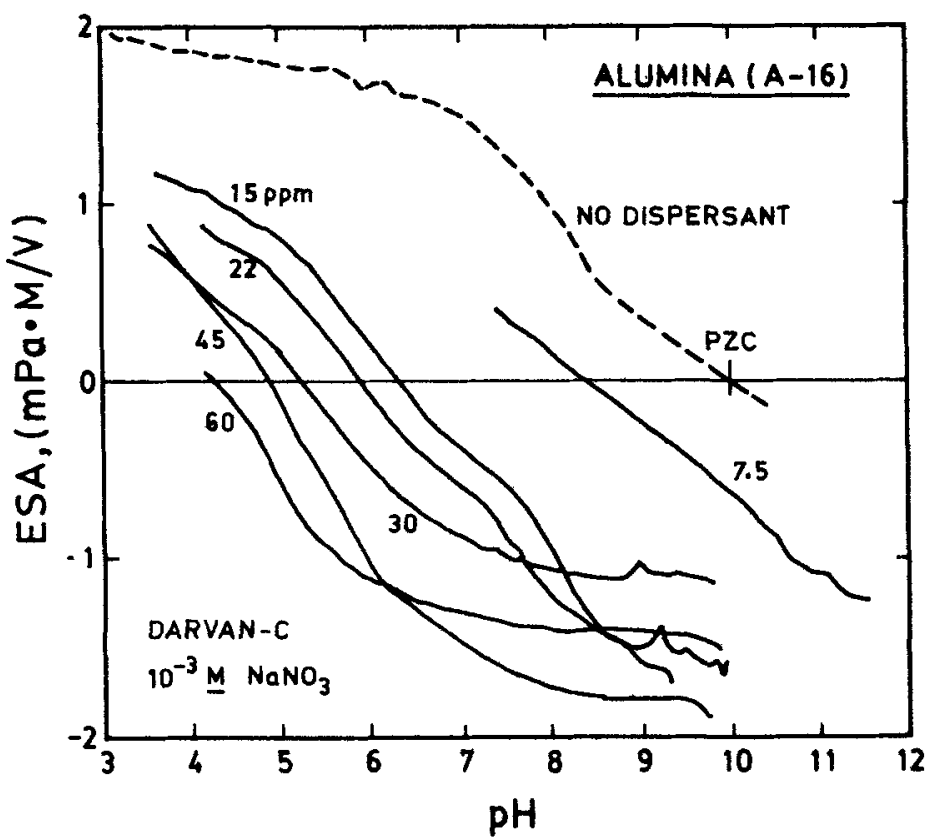

Figure 1. Electro-acoustic measurements of alumina suspensions (1 vol.\%) in presence of Darvan-C.

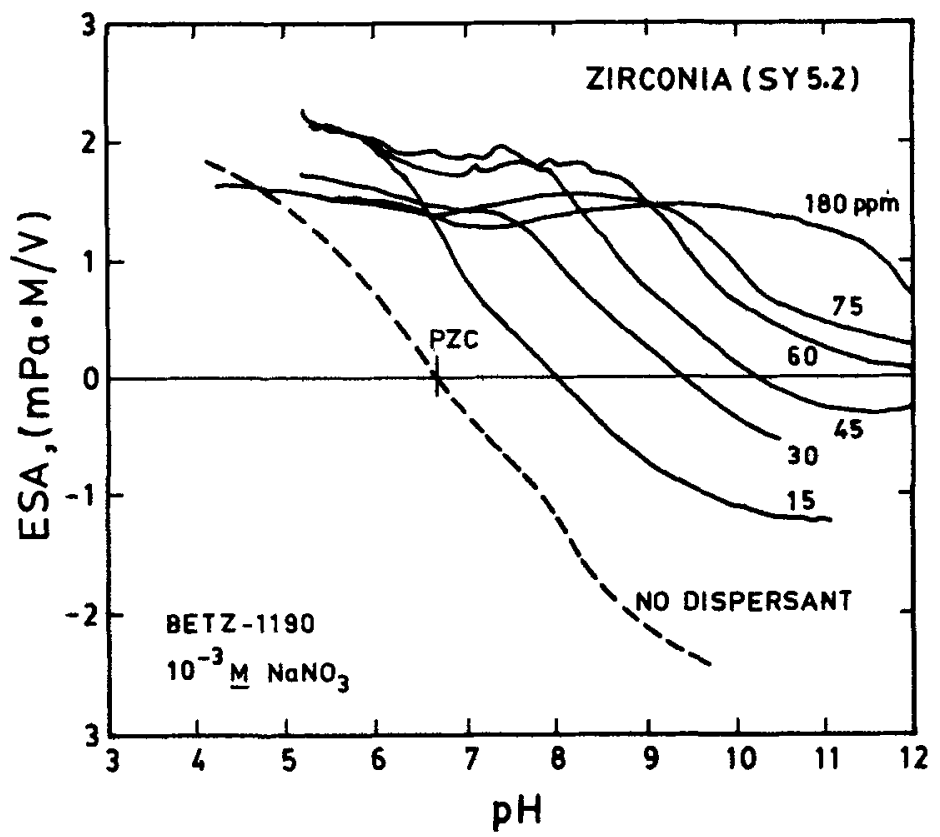

Figure 2. Electro-acoustic measurements on zirconia suspensions ( 1 vol.\%) in presence of Betz 1190. 


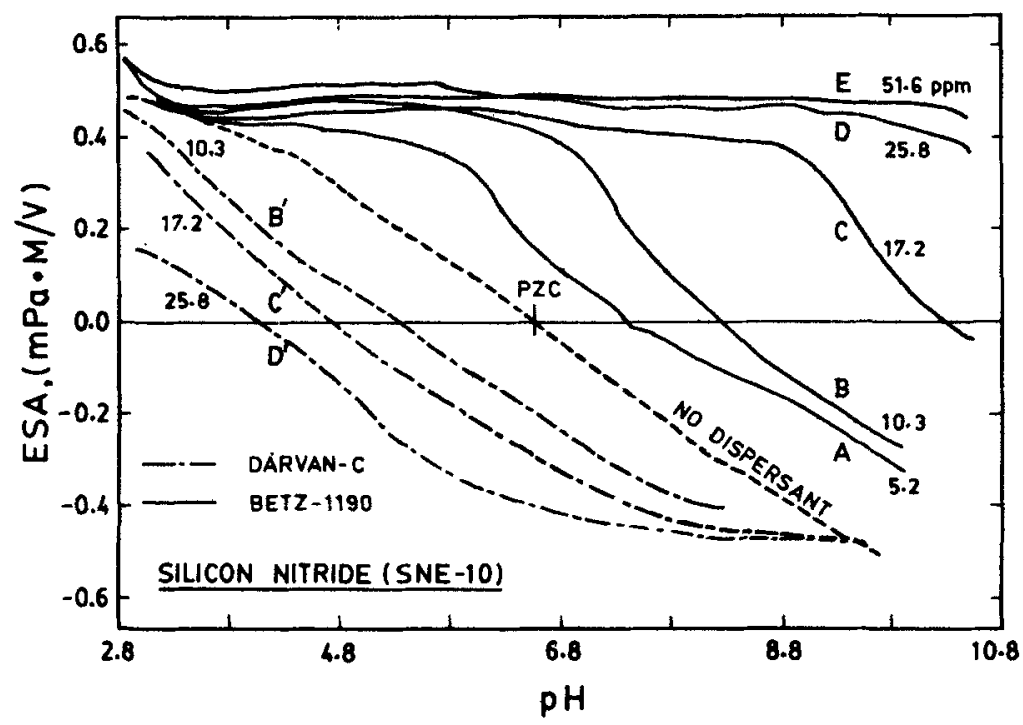

Figure 3. Electro-acoustic measurements on silicon-nitride suspensions $(0.5 \mathrm{vol} \%)$ in presence of Darvan-C and Betz 1190.

The corresponding dispersion experiments carried out in order to determine the optimum conditions for best dispersion indicated that at dispersant dosages and under $\mathrm{pH}$ conditions where the powder is close to its IEP, the dispersion was unsatisfactory. Some of the illustrative results are summarized in table 2 .

The results indicated that for good dispersion, indicated here by the mean size being close to the mean size of the powder, the polymer dosage and $\mathrm{pH}$ needs to be controlled such that the difference between the working $\mathrm{pH}$ and $\mathrm{pH}_{\mathrm{IEP}}$ of the powder (with or without dispersant as the case may be) is at least $2 \mathrm{pH}$ units. Under conditions close to IEP, irrespective of the polymer added, the suspension was always observed to coagulate. For example, in presence of Darvan- $C$, an anionic dispersant at dosages above $75 \mathrm{ppm}$, both alumina and zirconia exhibited an IEP of $\mathrm{pH} 4$. It is impossible, therefore, to disperse these powders with Darvan-C. In fact, both these powders can be dispersed well at $\mathrm{pH} 4$ without Darvan-C rather than in its presence. Addition of Darvan-C shifts the IEP to more acidic $\mathrm{pH}$ causing reduction in the repulsive interaction and hence deterioration in dispersion. This example clearly illustrates the role of electrostatic interactions in the dispersion of powders. One would expect a polymeric dispersant like Darvan to function primarily through steric stabilization mechanism and hence not be sensitive to $\mathrm{pH}$. But it is not so. The absence of electrostatic repulsion at $\mathrm{pH}$ close to IEP leads to aggregation-the steric interactions appear to be inadequate to overcome the van der waals attraction.

It is thus concluded that a judicious combination of dispersant dosage and $\mathrm{pH}$ condition (at least $2 \mathrm{pH}$ units away from IEP) is essential for achieving dispersion of powders using commercial polyelectrolytes. It is therefore recommended to establish the IEP of the slurry in presence of the dispersant under consideration before attempting evaluation of its efficacy. The results indicated that for alumina, 
Table 2. Correlation of the extent of dispersion as measured through $d_{50}$, the mean size.

\begin{tabular}{|c|c|c|c|c|}
\hline \multirow[b]{2}{*}{ System } & \multirow[b]{2}{*}{$\mathrm{pH}_{\mathbf{i}}$} & \multirow[b]{2}{*}{$\left(\mathrm{pH}_{\mathrm{i}}-\mathrm{pH}_{\mathrm{IEP}}\right)^{*}$} & \multicolumn{2}{|c|}{ Dispersion } \\
\hline & & & $d_{50}(\mu \mathrm{m})$ & Remarks \\
\hline $\begin{array}{l}\text { Alumina (A-16) } \\
\left.\text { No dispersant (pH }{ }_{\text {IEP }} 9.9\right)\end{array}$ & $\begin{array}{r}4 \\
10\end{array}$ & $\begin{array}{l}5 \cdot 9 \\
1 \cdot 1\end{array}$ & $\begin{array}{l}0.38 \\
3.59\end{array}$ & $\begin{array}{l}\mathbf{W} \\
\mathbf{N}\end{array}$ \\
\hline With 75 ppm Darvan-C $\left(\mathrm{pH}_{\mathrm{IEP}} 4.5\right)$ & $\begin{array}{r}4 \\
10\end{array}$ & $\begin{array}{l}0.5 \\
5 \cdot 5\end{array}$ & $\begin{array}{l}4 \cdot 18 \\
0.38\end{array}$ & $\begin{array}{l}\mathrm{N} \\
\mathrm{W}\end{array}$ \\
\hline With $150 \mathrm{ppm}$ Betz $1190\left(\mathrm{pH}_{\text {IEP }}>10\right)$ & $\begin{array}{l}4 \\
8 \cdot 1\end{array}$ & $\begin{array}{l}>6 \\
>2\end{array}$ & $\begin{array}{l}0.39 \\
0.38\end{array}$ & $\begin{array}{l}\mathbf{W} \\
\mathbf{W}\end{array}$ \\
\hline $\begin{array}{l}\text { Zirconia (SY 5.2) } \\
\quad \text { No dispersant }\left(\mathrm{pH}_{\mathrm{IEP}} 6.65\right)\end{array}$ & 4 & $2 \cdot 7$ & 0.21 & W \\
\hline With $75 \mathrm{ppm}$ Darvan-C $\left(\mathrm{pH}_{\text {IEP }} 4\right)$ & $\begin{array}{l}4 \\
7.4 \\
9.1\end{array}$ & $\begin{array}{r}-0 \\
3.4 \\
5.1\end{array}$ & $\begin{array}{l}9.8 \\
0.21 \\
0.21\end{array}$ & $\begin{array}{l}\mathbf{N} \\
\mathbf{W} \\
\mathbf{W}\end{array}$ \\
\hline With $150 \mathrm{ppm}$ Betz $1190\left(\mathrm{pH}_{\text {IEP }}>12\right)$ & $6 \cdot 3$ & $>5.7$ & 0.21 & W \\
\hline Silicon nitride (SNE-I0) & & & & \\
\hline With 25 ppm Darvan-C ( $\left.\mathrm{pH}_{\mathrm{IEP}} 4 \cdot 1\right)$ & 9 & 4.9 & 0.4 & W \\
\hline With $25 \mathrm{ppm}$ Betz $1190\left(\mathrm{pH}_{\mathrm{IEP}}>12\right)$ & 9 & $>3$ & 0.4 & W \\
\hline
\end{tabular}

*The electrical double layer repulsion increases with increasing $\left(\mathrm{pH}_{\mathrm{i}}-\mathrm{pH}_{1 \mathrm{Ep}}\right)$. W, Well dispersed; N, No dispersion.

zirconia and silicon-nitride powders, a cationic polymer like Betz could be used quite effectively. With Darvan-C, on the other hand, the dispersion was possible only at alkaline $\mathrm{pH}$.

\section{Electrokinetics of dispersant adsorption}

Another important observation worth noting in the results presented in figures 1 to 3 is the characteristic shift in the isoelectric point observed with addition of dispersants. The magnitude of this shift in IEP is a measure of the affinity of the adsorbing dispersant for powder surface. Following the electrical double layer theory of surfactant adsorption (Somasundaran and Fuerstenau 1966; Wakamatsu and Fuerstenau 1968; Osseo Asare and Fuerstenau 1973; Hunter 1981; Pradip and Fuerstenau 1983), Pradip (1988) recently established an explicit relationship between the characteristic shift in IEP and the concentration of the chemisorbing surfactant in solution. Using this equation, it is possible to compute the specific free energy of interaction for each powder-dispersant combination and to thus compare the relative efficiency of various dispersants for a particular powder under consideration. An attempt has been made in this section to confirm the validity of this relationship.

Assuming Stern-Grahame type of adsorption isotherm for the dispersants adsorbing at a ceramic powder surface,

$$
\theta / 1-\theta=c / 55.5\left[\exp \left(-\Delta G_{\mathrm{ads}}^{\mathrm{N}} / R T\right)\right] \text {, }
$$


where $\theta=\left(\Gamma_{\delta} / \Gamma_{m}\right)$ is the fractional surface coverage at equilibrium concentration in moles/litre in solution. $\Gamma_{\delta}$ and $\Gamma_{m}$ represent the adsorption density in mole $/ \mathrm{cm}^{2}$ at concentration $c$ and at saturation (monolayer coverage) level respectively. Furthermore, the cross-sectional area of dispersants is assumed to be around $20-25 \AA^{2}$ which means that $\Gamma_{m}$ is $7 \times 10^{-10} \mathrm{~mole} / \mathrm{cm}^{2}$. The inner layer capacity of the double layer at the ceramic surface is assumed to be $20 \mathrm{microfarad} / \mathrm{cm}^{2}$. Following Pradip (1988), one can then derive that

$$
\Delta \mathrm{pH}_{\mathrm{IEP}}=1.0396 C_{0} \exp \left(-\Delta G_{\mathrm{sp}}^{0} / R T\right),
$$

where $\Delta \mathrm{pH}_{\mathrm{lEP}}$ is the shift in the iso-electric point at the dispersion concentration $C_{0}$ and $-\Delta G_{\mathrm{sp}}^{0}$ represents the corresponding specific energy of interaction between the ceramic powder surface and the dispersant. $R$ and $T$ are the standard gas constant and the temperature in ${ }^{\circ} \mathrm{K}$.

The assumptions enumerated above are reasonable for the system under consideration. More precise calculations can, of course, be carried out if the data regarding the adsorption isotherm and the cross-section area of the adsorbing molecules is also available.

The electrokinetic behaviour of a solid surface in the presence of an adsorbing surfactant (cationic or anionic) can be schematically described as shown in figure 4. For a solid surface having an IEP at $A$ (also known as the point of zero charge $(P Z C)$ ), i.e. IEP in absence of the dispersant, the IEP will shift towards more

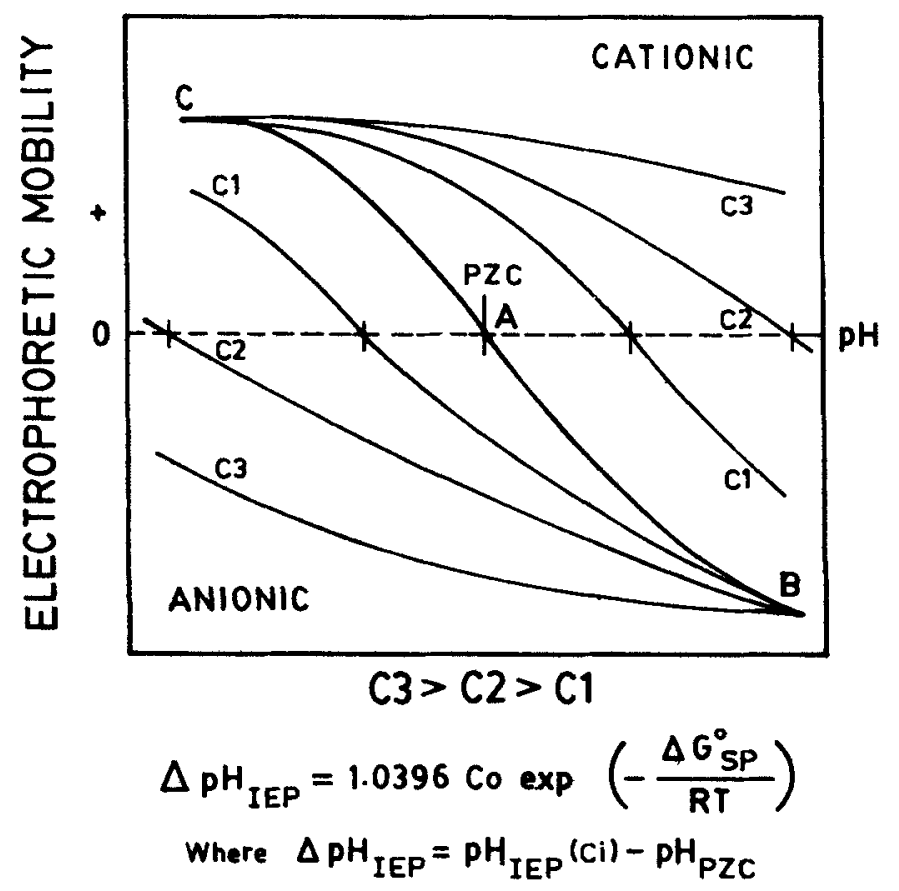

Figure 4. A schematic explaining the effects of anionic and cationic dispersants on the isoelectric point (IEP) of powders. 
acidic $\mathrm{pH}$ in presence of an anionic surfactant and towards more alkaline $\mathrm{pH}$ with addition of a cationic surfactant. At a pH sufficiently away from PZC such as at and above points $B$ and $C$, the electrokinetic behaviour of the powder in the presence of dispersant exactly follows the behaviour observed in its absence. This is due to the fact that under these conditions the specific energy of interaction (attractive) between the adsorbing surfactant and the surface is exactly counter-balanced (equal and opposite) by the electrostatic energy of repulsion between the similarly charged surface and the adsorbing molecule. Hence, the adsorption is zero. At points $B$ and $C$,

$$
\Delta G_{\mathrm{sp}}^{\prime \prime}=-\Delta G_{\mathrm{elec}}^{0}
$$

and thus

$$
\Delta G_{\mathrm{ads}}^{0}=\Delta G_{\mathrm{sp}}^{\mathrm{l}}+\Delta G_{\mathrm{elec}}^{0}=0
$$

The specific energy of interaction $\Delta G_{\mathrm{sp}}^{0}$ for each of the dispersant powder combination studied during this work was computed following (2). The results are presented in table 3 and figure 5 indicating confirmation of our assumptions.

A $\log -\log$ plot for $\mathrm{pH}_{\text {IEP }}$ vs the concentration in solution should exhibit a slope of unity as per (2). As illustrated in figure 5, except for a slight discrepancy in case of alumina Darvan- $C$ at higher dosages, the proposed equation fits the data remarkably well. The specific interaction energies thus computed were found to be between -13.5 to $-14.7 R T(8-9 \mathrm{Kcal} / \mathrm{mole})$ for all the four powder-dispersant combinations investigated as part of this work. It suggests that both Darvan-C

Table 3. $\Delta G_{\mathrm{sp}}^{0}$, as estimated by (2), assuming the dispersant molecular weight for both Darvan-C and Betz 1190 to be 10,000 .

\begin{tabular}{lccc}
\hline System & $C_{0}(\mathrm{ppm})$ & $\Delta \mathrm{pH}_{\mathrm{IEP}}$ & $\Delta G_{\mathrm{sp}}^{0}(R T$ units $)$ \\
\hline Alumina (A-16) & & & \\
Darvan-C & 7.5 & 1.6 & -14.5 \\
& 22.5 & 3.7 & -14.7 \\
& 30 & 4.1 & -14.4 \\
& 45 & 5.1 & -14.2 \\
& 60 & 5.7 & -13.9 \\
Zirconia (SY 5.2) & & & -13.7 \\
Betz 1190 & 15 & 1.35 & -13.7 \\
& 30 & 2.75 & -13.7 \\
& 45 & 3.55 & -13.5 \\
Silicon nitride (SNE-10) & 60 & 5.55 & -13.7 \\
Darvan-C & & & -13.9 \\
& 10.3 & 1.2 & -13.8 \\
& 17.2 & 1.8 & -13.7 \\
Silicon nitride (SNE-10) & 25.8 & 2.4 & -14.2 \\
Betz 1190 & & & -14.3 \\
& 5.2 & 0.8 & -14.6 \\
\hline
\end{tabular}




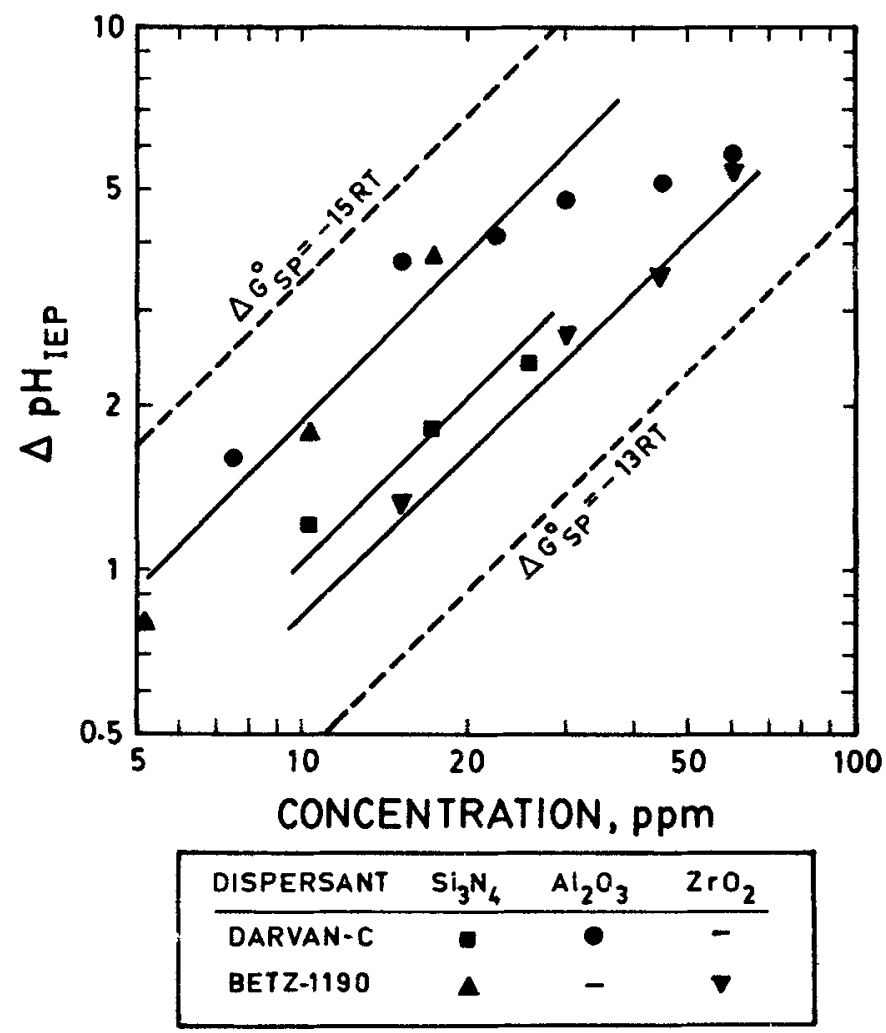

Figure 5. A plot of the shift in isoelectric point $\Delta \mathrm{pH}_{\mathrm{IEP}}$ for alumina, zirconia and silicon nitride suspensions as a function of concentration in solution (2). The dotted lines represent the relationship predicted by (2) for varying specific energies of interaction $\Delta G_{\mathrm{sp}}^{\text {) }}$.

(essentially containing carboxylic acid functional groups) and Betz 1190 (containing amine functional groups) adsorb quite strongly at alumina, zirconia and silicon-nitride surfaces.

\section{Conclusions}

The dispersion of three different ceramic powders was studied using two polyelectrolytes, one cationic (Betz 1190) and the other anionic (Darvan-C). The results strongly indicated the importance of electrical double layer repulsive interactions in achieving dispersion of ceramic powders. It was observed that the steric forces alone are not sufficient to overcome the attractive van der waals forces, under $\mathrm{pH}$ conditions close to the $\mathrm{pH}_{\mathrm{IEP}}$ of the powder-dispersant combinations, at least for the low molecular weight polymeric dispersants investigated during this work. The working $\mathrm{pH}$ must therefore be at least two $\mathrm{pH}$ units away from the $\mathrm{pH}_{\mathrm{iEP}}$ of the powder-dispersant combinations for good dispersion.

The observed shift in the IEP as a consequence of dispersant addition was found to be consistent with the electrical double layer model of surfactant adsorption. 
The estimated specific energies of interaction for the powder-polyelectrolyte combinations studied as part of this investigation were in the range of $8-9 \mathrm{Kcal} / \mathrm{mole}$, indicating strong affinity between the polyelectrolyte and the ceramic surfaces.

\section{Acknowledgements}

Financial support for this work from US-India Fund under Indo-US collaborative programme between the Department of Science and Technology (DST), India and the National Institute of Standards and Technology (NIST), USA is gratefully acknowledged. One of us (P) is grateful to Prof. E C Subbarao for his keen interest in this work and for critically reviewing the manuscript. The authors thank $\mathrm{Dr} \mathrm{V} \mathrm{A}$ Hackley and Dr P T Pei for their help in carrying out electro-acoustic measurements.

\section{References}

Bleier A 1992 Colloids Surf. 66157

Bleier A and Westmoreland C G $1991 \mathrm{~J}$. Am. Ceram. Soc. 743100

Bleier A, Beecher P F, Alexander K B and Westmoreland C G 1992 J. Am. Ceram. Soc. 752649

Calvert P D, Tormey E S and Pober R L 1986 Am. Ceram. Soc. Bull. 65669

Chou K and Lee L $1989 \mathrm{~J}$. Am. Ceram. Soc. 721622

Hackley V A, Premachandran R S and Malghan S G 1993 Characterization techniques for the solid-solution interface (eds) J H Adair, I A Casey and S Venigalla (Ohio, USA: American Ceramic Soc.) p. 141

Hogg R, Healy T W and Fuerstenau D W 1966 Trans. Faraday Soc. 621638

Hunter R J 1981 Zeta potential in colloid science (London: Academic Press)

Israelachvili J 1992 Intermolecular and surface forces (London: Academic Press) Second edition

Lange F F $1989 \mathrm{~J}$. Am. Ceram. Soc. 723

Leong Y K, Boger D V and Parris D 1991 Trans. Inst. Chem. Eng. 69381

Malghan S G (ed.) 1993 Electroacoustics for characterization of particulates and suspensions (USA: NIST)

Napper D H 1983 Polymeric stabilization of colloidal dispersions (New York: Academic Press)

Osseo-Asare K and Fuerstenau D W 1973 Croatica Chemica Acta 45149

Pradip 1988 Trans. Indian Inst. Metals 4115

Pradip and Fuerstenau D W 1983 Colloids Surf: 8103

Premachandran R S and Malghan S G 1994 Powder Technol. (in press)

Somasundaran P and Fuerstenau D W 1966 J. Phys. Chem. 7090

Sung A and Piirma I 1994 Langmuir 101393

Wakamatsu T and Fuerstenau D W 1968 in Adsorption from aqueous solution, adv. in chemistry (New York: American Ceramic Soc.) p. 161 